\title{
Nota sobre los artículos seleccionados para el presente número conmemorativo
}

\author{
Note on the articles selected for this \\ commemorative issue
}

ANTONIO DIÉGUEZ

Director de Contrastes

Recibido: 29/09/20 Aceptado: 29/09/20

\begin{abstract}
RESUMEN
Breve explicación de la selección de textos para este volumen conmemorativo.

PALABRAS CLAVE

VOLUMEN CONMEMORATIVO, CONTRASTES, SELECCIÓN DE TEXTOS,

AUTORES, ÁREAS

ABSTRACT

Brief explanation of the selection of texts for this commemorative volume.

KEY WORDS

COMMEMORATIVE ISSUE, CONTRASTES, SELECTION OF TEXTS, AUTHORS, FIELDS
\end{abstract}

NO ES FÁCIL, DESPUÉS DE tantos años de andadura, hacer una selección de los artículos más interesantes, significativos o influyentes entre todos los publicados por Contrastes a lo largo de su historia. Tampoco lo hemos pretendido. Solo hemos hecho una selección pensando en el interés del lector actual. Ha habido, sin embargo, un criterio temporal que, por razones técnicas, ha constreñido nuestra selección. Con anterioridad al volumen 11, publicado en 2006, los documentos en pdf de los artículos fueron realizados mediante escaneo de la revista en papel. Esto implicaba que la selección de

(C) Contrastes. Revista Internacional de Filosofía, vol. XXV Nº3 (2020), pp. 11-12. ISSN: 1136-4076

Departamento de Filosofía, Universidad de Málaga, Facultad de Filosofía y Letras Campus de Teatinos, E-29071 Málaga (España) 
cualquier artículo anterior a ese volumen exigiera la reescritura del mismo en documento digital, lo que habría dificultado enormemente la edición del presente número. Así que se han seleccionado artículos posteriores a esa fecha, con dos excepciones: el artículo de Ilkka Niiniluoto y el de Victoria Camps. La razón de estas excepciones es muy simple: alguno de nosotros conservaba el archivo digital dichos artículos.

Cada una de las cuatro áreas de conocimiento que componen el Departamento de Filosofía de la Universidad de Málaga ha elegido dos artículos para este número. El Área de Filosofía seleccionó el artículo de Wilhelm G. Jacobs "La esencia de la libertad en el enfrentamiento entre Jacobi y Schelling", que se publicó originariamente en el suplemento 19 El idealismo alemán y sus consecuencias actuales, de 2014, y el artículo de Andrzej Przylebski "Dilthey y el giro antropológico de la filosofia", publicado anteriormente en el volumen 19, número 2, de ese mismo año de 2014. El Área de Filosofía Moral seleccionó el artículo de Victoria Camps "Derechos de la mujer y derechos universales", publicado en el suplemento 5 Retos pendientes en ética y política, del año 2000, y el de José Rubio Carracedo "Algunas reformas institucionales pendientes", publicado en el volumen 13 de 2008. El Área de Lógica y Filosofía de la Ciencia seleccionó el artículo de Ilkka Niiniluoto "Escepticismo, falibilismo y verosimilitud", publicado originalmente en el suplemento 3 de 1998 Filosofía actual de la ciencia (un número, por cierto, que cuenta con colaboraciones de Ronald Giere, Nicholas Rescher, Susan Haak y Javier Echeverría, entre otros) y la entrevista que Antonio Diéguez le hizo a Anders Sandberg bajo el título de "Una mirada al futuro de la tecnología y del ser humano. Entrevista con Anders Sandberg", que se publicó en español en el volumen 20, número 2, de 2015. Ahora ofrecemos al lector el original en inglés. Finalmente, el Área de Estética y Teoría de las Artes seleccionó el artículo de Yuriko Saito "Everyday Aesthetics and World-Making", publicado originalmente en el número monográfico 17 Estética e interculturalidad, de 2012, y el artículo de César Moreno Márquez "Una suerte de calma hechizada. Praxis de extrañamiento y trascendencia poética (Paseando por el Rastro con Gómez de la Serna)", publicado en el volumen 21, número 3, de 2016. 